University of Warwick institutional repository: http://go.warwick.ac.uk/wrap

This paper is made available online in accordance with publisher policies. Please scroll down to view the document itself. Please refer to the repository record for this item and our policy information available from the repository home page for further information.

To see the final version of this paper please visit the publisher's website. Access to the published version may require a subscription.

Author(s): Brewer, B.

Article Title: Perception and its objects

Year of publication: 2007

Link to published article : http://dx.doi.org/10.1007/s11098-006-9051-2

Publisher statement: The original publication is available at www.springerlink.com Brewer, B. (2007). Perception and its objects. Philosophical Studies, 132(1), pp. 87-97. 


\section{PERCEPTION AND ITS OBJECTS}

BILL BREWER

Here is an influential inconsistent triad of claims concerning the nature of perceptual experience and its objects.

(1) Physical objects are mind-independent.

(2) Physical objects are the direct objects of perception.

(3) The direct objects of perception are mind-dependent.

Physical objects are such things as stones, tables, trees, people and other animals: the persisting macroscopic constituents of the world we live in. For the entities of a given kind to be mind-independent is for them to exist, and be intrinsically as they are, independently of anyone's thought or experience of them. Otherwise they are minddependent in some way.

According to the early modern empiricists, especially Locke (1975) and Berkeley (1975a, 1975b), the core subjective character of a perceptual experience is to be given simply by citing the object presented in that experience. In line with that approach, the direct objects of perception are those objects, if any, which constitute its core subjective character, which identify any given perceptual experience as the specific core modification of consciousness which it is. There may be experiences which cannot be characterized in 
this way: their subjective character has to be given otherwise than by reference to any particular such object; and, although such experiences may be related in various ways to objects of various other kinds, none of these is their direct object in my technical sense.

(1) expresses a commonsense commitment to what might be called physical realism. I take (2) to be the most natural expression of the equally commonsense idea that physical objects are the objects which are presented to us in perception, whose nature is made evident to us by the subjective character of our perceptual experience. We shall see, though, that there is an alternative strategy for retaining the idea that physical objects are the very things which are presented to us in perception, which we see, feel, hear, and so on, without regarding these as direct objects in my sense. Still, the conjunction of (1) and (2) provides the most natural formulation, at least, of empirical realism, the intuitive thesis that the objects which are presented to us in perception, such as stones, tables, trees, people and other animals, nevertheless exist, and are intrinsically as they are, quite independently of our perception of them, and, indeed, of anyone's thought or experience of them.

(3) is the conclusion of a philosophical argument: the argument from illusion. Very crudely, in cases of illusion, the direct object of perception has a property which no candidate mind-independent object has, and must therefore be mind-dependent; then, since every perceptual experience is subjectively identical to one in a possible case of illusion, the same goes across the board. The direct objects of any perception are always mind-dependent. This line of argument may be made precise in a number of importantly 
different ways. I think that Paul Snowdon is right to distinguish two phases in each of them (1992). The first is intended to establish that the direct object of an illusion is minddependent. The second is supposed to generalize this result to all perceptual experience, including that involved in veridical perception. There are serious problems with any version of phase two which I know. It is sufficient for my purposes here, though, to elaborate phase one as follows.

A visual illusion may be characterized as an experience in which a physical object, $\underline{\mathrm{o}}$, looks $\underline{\mathrm{F}}$, although $\underline{\mathrm{o}}$ is not actually $\underline{\mathrm{F}}{ }^{1}$ According to the early modern empiricist insight, the way to account for the fact that something looks $\underline{F}$ in an experience is to construe that experience as the presentation to the subject of a direct object, which constitutes the core subjective character of the experience, and which must, therefore, supposedly, actually be F. In cases of illusion, then, this direct object is distinct from the physical object $\underline{o}$ which is not $\underline{F}$.

On Locke's materialist view, indirect realism, the direct object of an illusion is a minddependent entity, which is $\underline{F}$, which nevertheless sufficiently resembles a non- $\underline{F}$, mindindependent object, $\underline{\mathrm{o}}$, for the latter to be the physical object which illusorily looks $\underline{\mathrm{F}}{ }^{2} \mathrm{On}$

\footnotetext{
${ }^{1}$ I concentrate throughout on the case of vision. I believe that much of what I say applies equally to the other modalities, although I do not address this here. There are plausible counterexamples to the sufficiency of this characterization of visual illusion; but it is adequate for present purposes. My forthcoming 'How to Account for Illusion', and Perception and its Objects, contain further discussion.

${ }^{2}$ Things are of course more complicated in case of secondary qualities, according to Locke. For, in one sense, all secondary quality perception is illusory: nothing in the mind-independent physical world is red, in the basic sense in which mind-dependent ideas are red. Still, in having such an idea before the mind, a physical thing may be said
} 
the most straightforward version of Berkeley's mentalism, on the other hand, the direct object of an illusion is a mind-dependent entity, which is a part of an equally minddependent composite physical object $\underline{\underline{0}}$. $\underline{\mathrm{O}}$ is not $\underline{\mathrm{F}}$, very roughly, because most of its parts are not $\underline{\mathrm{F}}$, and it does not behave, in general, in ways characteristic of F's: in particular we cannot use it as we can paradigm F's. Nevertheless, it looks $\underline{F}$, on this occasion, because the part presented in the relevant illusory experience is $\underline{F}^{3}$ Both approaches are widely regarded as unsatisfactory today, absolutely rightly in my view. ${ }^{4}$

According to current orthodoxy, the mistake goes right back to the idea that perceptual experience has its core subjective character given simply by citing its direct object, which must apparently therefore be $\underline{F}$ in a case of illusion, and hence must be distinct from the physical object, $\underline{\mathbf{o}}$, which illusorily looks $\underline{\mathrm{F}}$ although it is not. The subjective character of perceptual experience is to be given instead by its representational content: how it represents things as being in the physical world around the subject. In an illusion, perception has the false representational content that $\underline{\mathrm{o}}$ is $\underline{\mathrm{F}}$. In general, $\underline{\mathrm{o}}$ looks $\underline{\mathrm{F}}$ iff $\underline{\mathrm{o}}$ is

to look red*, that is, either disposed to produce red ideas in normal observers in normal conditions, or microscopically constituted in whichever way actually grounds that disposition. Some, but not all, such perceptions may then be illusory in a derived sense, in which something looks red* which is not. None of these details are relevant for present purposes.

${ }^{3}$ See Stoneham (2002) for a compelling presentation of this account of Berkeley. Note, as with Locke's account of the secondary qualities, predicates apply to persisting physical objects, according to Berkeley, in a way which is derivative of their more basic application to our fleeting ideas, which are their temporal, and 'personal', parts. ${ }^{4}$ Having said that, I believe that there are significant, and illuminating, structural similarities between the latter Berkeleyian view, and Lewis' (1998) account of the metaphysics of persisting (that is, in his view, perduring, rather than enduring) macroscopic physical objects, especially in the presence of his Ramseyian humility (2002). My forthcoming 'Berkeley and Modern Metaphysics', and Perception and its Objects, contain detailed development of this suggestion. 
the referent of a perceptual content in which $\underline{\mathrm{F}}$ is predicated. I call this the Content View, (CV), since it characterizes perceptual experience by its representational content, and identifies the objects of perception as those to which reference is made by such contents. (CV) rejects (3) from my opening inconsistent triad, by rejecting the early modern empiricist idea which gives the notion of a direct object its sense: there are no direct objects in this sense.

I believe that $(\mathrm{CV})$ is a mistake. My aim in this paper is to begin a rehabilitation of the early modern empiricist insight, as I see it, that the core subjective character of perceptual experience is simply constituted by the objects presented in that experience. I argue that this is perfectly consistent with the empirical realist contention, even in cases of illusion, that these direct objects are the persisting mind-independent physical objects we all know and love. I call this the Object View $(\mathrm{OV}) .(\mathrm{OV})$ also rejects (3), this time by insisting that the direct objects crucial to understanding perception, as the early modern empiricists contend, are perfectly mind-independent physical things.

I begin, though, with a brief sketch of what I regard as a series of highly suggestive problems which $(\mathrm{CV})$ encounters in reconciling its approach to illusion, in terms of false representational content, with the idea that the objects of visual illusion are themselves subjectively presented in such experience. ${ }^{5}$ The fundamental intuition is that (CV) induces a significant distortion, by forcing materials pertaining to a person's conceptual

\footnotetext{
${ }^{5}$ My forthcoming 'Perception and Content', and Perception and its Objects, contain extended critical investigation of $(\mathrm{CV})$, in which the following difficulties are developed at length.
} 
thought about the world presented in perception into its account of the most basic nature of perceptual experience itself. Selective categorization of particular constituents of physical reality enters the picture of a person's relation with the world around her only when questions of their various similarities with, and differences from, other such things somehow become salient in thought about them, rather than constituting an essential part of their basic subjective presentation in perception. Perception itself constitutes the fundamental ground for the very possibility of any such abstract general thought about the physical world subjectively presented in it. In assimilating experience to thought, (CV) misses what is fundamental to its subjective character.

Consider the Müller-Lyer illusion, (ML), for example, in which two lines which are actually identical in length are made to look different in length by the addition of misleading hashes. Rejecting any appeal to two mind-dependent items which actually differ in length, as we surely must, the proponent of (CV) insists that we describe this as a case in which the two lines are falsely represented in visual experience as being of unequal length.

Is the line with inward hashes supposed to be represented as shorter than it actually is, though; or is the line with outward hashes represented as longer than it actually is; or both; and by how much in each case? That is to say, how exactly would the world have to be for the purported perceptual representation to be veridical? (CV)'s talk of perceptual content requires a specific answer to this question. Yet it far from clear how one is nonarbitrarily supposed to be given. 
It might be replied that perception represents the (ML) lines, merely determinably, as one a little longer than the other, rather than assigning either a very determinate length or any real determinacy to the degree of their difference in length. This comes at a cost, though, for it forfeits the $(\mathrm{CV})$ theorist's preferred account of the fine-grainedness of perception, crucial to distinguishing experiential representation from representation in thought, on this approach, as consisting in the maximal degree of determinateness in perceptual content, as opposed, often at least, to the more determinable contents which figure in thought (see e.g. Evans, 1982, p. 229; Peacocke, 1992; McDowell, 1994, Lect. III and Afterword, Pt. II; Brewer, 1999, 5.3.1).

Now, consider the four endpoints of the two main lines in the (ML) diagram. Surely these may experientially be represented as being where they actually are, at just those four places in space, according to (CV). Indeed, looking at the diagram head-on, in good viewing conditions, and raising the question in turn where each endpoint looks to be, (CV) seems to me to be committed to this description. At the same time, the illusory nature of the experience supposedly consists in the fact that the lines are also represented as being different in length. In that case, the representational content of the (ML) experience is impossible. It cannot possibly be veridical, not even when faced by the diagram itself, in perfect viewing conditions. This strikes me as an unattractive result. For surely one is seeing precisely what is there - lines on the screen just where they are and nowhere else - however misleading that very diagram may be. 
There is a further, related, tension, in my view, between the (CV) approach to illusion as false perceptual representation, and the idea that the physical objects of illusion are genuinely subjectively presented in illusory experience. The scope for error introduced by the account of illusion threatens to undermine the phenomenon of perceptual presentation. I can certainly think, of a figure which you hide behind a screen, that it is square, when actually it is circular; but, if we insist on characterizing my perceptual experience as a representation as of a square figure before me, then how can we simultaneously claim that what is actually a circle is thereby subjectively presented to me, even if there actually is a circle out there, where I represent a square as being, which is somehow causally relevant to my purported perceptual representation? Although error in predication of this kind, or far worse, is no obstacle to reference in thought, it makes a mockery of presentation in experience.

I suggest, then, that illusion forces us to distinguish two quite different levels in perception. (OV), as I shall develop it, respects this, in distinguishing the mindindependent direct object, which constitutes the core subjective character of the experience, from the various ways in which this might perfectly intelligibly be taken to be, seen from the subject's point of view in the given circumstances of perception, and so on, in virtue of its visually relevant similarities with paradigms of various kinds. (CV) is torn, though, between, either leaving the mind-independent object itself out of the

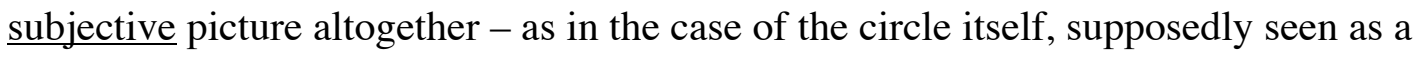
square, above - or forcing both into an impossible representational content - as in the 
case of the (ML) lines simultaneously represented as extended between equally distant endpoints, and yet unequal in length.

So, what is the Object View, and how does it account for illusion? The basic idea is that the core subjective character of perceptual experience is given simply by citing the physical object which is its mind-independent direct object. From various points of view, and in various circumstances of perception, physical objects have visually relevant

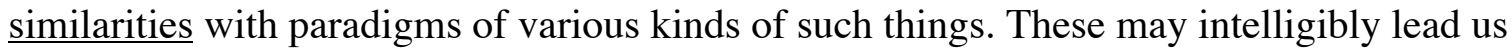
to take them as instances of such kinds when seen from the relevant points of view in the circumstances in question. Thus, they look various ways to us. Illusions are cases in which the direct object of experience has such similarities with paradigms of a kind of which it is not in fact an instance.

For example, the (ML) diagram is visually-relevantly similar to a pair of lines, one longer and more distant than its plane, one shorter and less distant, projecting into the diagram itself on the plane. It is therefore perfectly intelligible how someone seeing it might take that very diagram as consisting of unequal lines, regardless of whether she does or not. In this sense: they look unequal in length.

Which similarities are visually relevant, though; for anything has unrestricted similarities with everything? Clearly, the visually relevant similarities cannot be defined as identities in the ways the relata are visually represented as being, or else (OV) depends upon $(\mathrm{CV})$. That is to say, we cannot simply say that two objects have visually relevant similarities 
just when there are sufficiently many common properties amongst those which each is visually represented as having. Rather, they are, according to (OV), to be what ground and explain the ways in which the relata may intelligibly be taken to be when seen. That is to say, two objects have visually relevant similarities when they share sufficiently many common properties amongst those which have a significant involvement in the physical processes underlying vision. Thus, and very crudely, visually relevant similarities are identities in such things as, the way in which light is reflected from the objects in question, in the given circumstances, and propagated to the subject's viewpoint. $^{6}$

What are the paradigms of physical kinds supposed to be? Again very roughly, these are instances of the kinds in question, whose association with the terms for those kinds partially constitutes our understanding of them, given our training in the acquisition of the relevant concepts: paradigm exemplars of the kinds in question relative to our grasp of the concepts for those kinds. ${ }^{7}$

I claim that the same account covers many of the most standard cases of visual illusion. Here is a second example, for further illustration, and also to set the scene for my discussion of an illuminating line of objection below.

\footnotetext{
${ }^{6}$ I entirely acknowledge that this is a very rough placeholder for what must in the end by a far more developed account of visually relevant similarities.

${ }^{7}$ This idea is clearly in need of far more extended discussion. It also involves a controversial account of concepts and their possession. To make progress here I will have to leave further elucidation and defence for another occasion; but see Fodor (1998) for strong opposition.
} 
A white piece of chalk illuminated with red light looks red. Again, the $(\mathrm{OV})$ proposal is that the core of the subjective character of such illusory experience is constituted by that very piece of chalk itself: a particular persisting mind-independent physical object. From the viewpoint in question, and given the relevant perceptual circumstances - especially the abnormally red illumination - it looks red. This consists in the fact that it has visually relevant similarities with paradigm red objects: the light reflected from it is like that reflected from such paradigms in normal viewing conditions.

How does (OV) account for hallucinations, in which nothing physical is subjectively presented. These have no mind-independent direct object. (OV) also rejects any characterization of hallucination in terms of purportedly mind-dependent direct objects. Rather, hallucinatory experiences have to be characterized by giving a qualitative description of a mind-independent scene, and saying that the subject is having an experience which she cannot distinguish by introspection alone from one in which the constituents of such a scene are the direct objects. No more positive characterization of the experience may be given. ${ }^{8}$

Now, hallucinations may be caused in many and varied ways, such as by taking certain drugs or getting a firm knock to the head. Other ways of bringing about hallucination may also involve distal external objects, sometimes relatively systematically. Indeed, this may even occur in cases in which the relevant mind-independent objects are also presented as direct objects of vision, supplemented, as it were, by their hallucinatory

\footnotetext{
${ }^{8}$ I rely heavily here upon Martin (2004).
} 
products. (OV) has the resources to account for some cases which may pretheoretically be classified as illusions in this way. Hermann's Grid, in which pale grey patches appear at the intersections of the white channels formed by a grid of closely spaced black squares, is plausibly a case in point.

You might object at this point that, in rejecting $(\mathrm{CV})$, and insisting that the core subjective character of perceptual experience is to be given simply by citing its mindindependent direct object, given the relevant point of view and circumstances of perception, (OV) misses entirely the crucial point: illusions like (ML) are experiential. The (ML) lines look, phenomenologically, unequal in length! ${ }^{9}$ I agree with the datum, but I disagree that only (CV), and not (OV), may accommodate it.

This can be illustrated by reflection on the phenomenon of aspect-seeing. In the most basic case, the concept 'duck' is intelligibly applicable on being presented with a particular mind-independent animal as the direct object of perception, in virtue of its visually relevant similarities with paradigms of duckhood. In this sense, it looks like a duck. Given the actual direct object involved, with its visually relevant similarities to what we take to be paradigms of duckhood, we can even apply this characterization of the experience to a child without the concept of a duck, if we wish, although the charactrerization makes essential reference to the paradigms constitutive of our grasp of that concept. All that is involved in her having the experience, though, is that that very animal is presented, with the similarities it actually has with various paradigms of ours,

\footnotetext{
${ }^{9}$ Thanks to Ian Phillips (draft) for pressing this objection very forcefully in his paper at the 2005 Warwick University Mindgrad conference.
} 
not that her experience in any way represents it as being any such way. Reference to that object, given her viewpoint and the relevant circumstances entirely captures this phenomenology. Noting the intelligible applicability of our concept of a 'duck', in virtue of the de facto similarities with our paradigm, we may see it as a duck. This is a further genuinely phenomenological affair; but the difference in how things are for us phenomenologically is no change in the core subjective character of the experience; it rather concerns our classificatory engagement with what is presented to us in it: that very duck. This is the phenomenology of conceptual categorization, or recognition, not that of basic experiential presentation, which is common throughout. Still, it is aptly titled phenomenology, all the same.

Similarly, suppose that I am presented with the duck-rabbit diagram (Jastrow, 1900; Wittgenstein, 1958). According to (OV) the core subjective character of my experience is given simply by that diagram itself. It actually has visually relevant similarities with my paradigms of both a duck and a rabbit. In this sense both concepts are intelligibly applicable, and it looks like both a duck and a rabbit, regardless of whether I notice either resemblance: perhaps it is presented at a peculiar angle, and I notice neither. Then I see it as a duck, say, this is again a phenomenological change, but one of conceptual classificatory engagement with the very diagram presented to me. Similarly, when I shift aspects, and see it as a rabbit, there is an alteration in this phenomenology of the categorization of what is presented. 
Consider now the case of (ML). Suppose that someone has the diagram visually presented to them, from head-on, and in good lighting conditions, with eyes open and a normally functioning visual system. According to (OV), the core subjective character of their visual experience is simply constituted by that diagram itself. From that viewpoint, and given the circumstances of perception, it has visually relevant similarities with a paradigm pair of unequal lines at different depths. In this sense, the concept of inequality in length is intelligibly applicable to its main lines, they look unequal in length. Again, we may even mark the de facto existence of these similarities by saying this of children or animals without the relevant concepts. This is genuine phenomenology, which flows directly from the identification of the direct object of the experience, given the viewpoint and relevant circumstances. It is fully captured by (OV) without any need for (CV). Possessing the concept, as I do, I may notice the intelligible applicability of 'unequal in length' to the direct object of my (ML) experience. This may be, either because the question of the relative length of its main lines becomes relevant, and I attend accordingly, having previously only been concerned with selecting the black figures from a range of differently coloured diagrams, say, or simply because the intelligible applicability of this concept jumps out at me, or captures my attention. In this more robust sense, the lines now look unequal in length to me, regardless of whether I actually judge them to be so. This is a perfectly genuinely phenomenological matter; but one which is again captured entirely by $(\mathrm{OV})$, along with my deployment of attention and active conceptual endowment, without any need for (CV). 
Return, now, to the case of a white piece of chalk illuminated with red light. I explained the way in which (OV) accounts for the fact that this illusorily looks red. (OV) appears equally committed to the claim that it looks white-in-red-light. For everything has visually relevant similarities with itself, however exactly these are to be defined; and this may well be a paradigm case some something which is white-in-red-light. This plausibly entails that the chalk looks white, simpliciter, which is suspect, at best. Furthermore, parity of reasoning presumably suggests that $(\mathrm{OV})$ is committed to the idea that a red piece of chalk in normal lighting conditions looks white-in-red-light, and therefore looks white too. This is surely completely unacceptable. ${ }^{10}$

Let me make a start at least on these difficult and fascinating cases by making explicit a distinction implicit in my discussion of aspect seeing. There are thin and thick notions of looking $\underline{F}$ : $\underline{o}$ thinly looks $\underline{\mathrm{F}}$ in an experience iff $\underline{\mathrm{o}}$ is its direct object and $\underline{\mathrm{o}}$ simply has visually relevant similarities with paradigm $\underline{F}$ 's; $\underline{o}$ thickly looks $\underline{F}$ iff $\underline{o}$ thinly looks $\underline{F}$ and the visually relevant similarities are salient for the subject. A suitable squiggle thinly looks quarter-note-rest-shaped to all of us; thickly only to some - those who recognize it (at least an attempt at) such. The duck-rabbit thinly looks both duck-like and rabbit-like; thickly at most one of these. The locution is I think standardly interpreted thickly, although the thin reading can certainly be made appropriate. When we see white chalk in red light, it thinly looks white-in-red-light, as well as red; it is very unlikely thickly to do so, without considerable stage setting; but then it may well be right to say it does: for example, when trying to pick out the white piece from a collection of differently coloured

\footnotetext{
${ }^{10}$ Many thanks to Anil Gupta, who raised this line of objection in his wonderful comments at the Pacific APA, 2006, in Portland.
} 
chalks in a setting in which we all know the light is abnormally red. The correct target looks white (in-red-light). A red piece of chalk in normal lighting also thinly looks whitein-red-light, as well as red. It would not normally thickly look so; but, again, given sufficient stage-setting, it may be brought to do so. Notice, though, that the sense in which the white chalk in red light, and the red chalk is normal light, thickly look white, when they do, given sufficient stage setting, is essentially indirect, involving an explicit conjunction elimination by the subject from salient similarities with a complex paradigm: of something white-in-red-light. Still, it seems to me that all this serves to confirm, rather than in any way undermine, the (OV) contention that various looks are the product of a stable core subjective character and varying, sometimes quite sophisticated, attentional/classificatory phenomena.

Far more should also be said about the role of intelligibility in (OV). What is it for $\underline{\mathrm{o}}$ to be such that it may intelligibly be taken to be $\mathrm{F}$ in virtue of its visually relevant similarities with paradigm $\underline{\text { F' }} ?^{11}$ This is, neither for the visually relevant similarities to cause the subject to judge that $\underline{\underline{o}}$ is $\underline{\mathrm{F}}$, nor for explicit reference to such similarities to figure in $\underline{\text { her }}$ reasoning to this conclusion. The former is neither necessary nor sufficient. We don't judge the (ML) lines of different lengths; and paranoia may produce judgements that everything is deadly, even though only some things really look it. The latter is certainly not necessary either. The (ML) lines thickly look different in length even to those without any idea of the explanation I gave. All I can offer here is this. In certain cases, when de facto visually relevant similarities bring the concept $\underline{F}$ to mind, categorization of the

\footnotetext{
${ }^{11}$ A second question from Gupta.
} 
object presented as an $\underline{F}$ strikes the subject as appropriate given the paradigms of $\underline{F}$ involved in her acquisition and understanding of that concept. The intelligibility involved here is that of retrospectively evident, appropriate subsumption of a particular under a general term, given the subject's understanding of the term in question. In such cases, $\underline{\underline{a}}$ is intelligibly taken to be $\underline{F}$.

I end with two concerns about whether my own final position is really an Object View, on the model of the early modern empiricists, or whether it is not better characterized as a variant of the currently orthodox Content View. ${ }^{12}$

First, given all the genuinely phenomenological complexities introduced by attention and classification, what is the force of the $(\mathrm{OV})$ mantra that the presented mind-independent physical objects constitute the core subjective character of perceptual experience. I clearly reject the early modern empiricist proposal that phenomenology fixes, and is fixed by, the properties of direct objects, which are therefore bound to be mind-dependent things. So what is the residual point of the constitution claim? I believe that perceptual experience makes thought about presented mind-independent physical objects possible: our grasp of which things these are is derived from experience. ${ }^{13}$ This does not depend upon the classical empiricist biconditional, that something looks $\underline{F}$ in an experience iff the sense-datum constitutive of that experience is $\underline{F}$. The relation which $(\mathrm{OV})$ proposes, between the way things look in experience and the natures of the physical objects

\footnotetext{
${ }^{12}$ The first of these engages a third issues raised by Gupta in Portland; the second was raised by Nicolas Bullot's very helpful comments at the Pacific APA.

${ }^{13}$ See Campbell, 2002, for a sustained and detailed development of this fundamkental empiricist conviction.
} 
presented in them, is nevertheless sufficiently tight to persist with the notion of constitution. In the ideal case, something looks $\underline{F}$ because $\underline{o}$ is presented in that experience and $\underline{\underline{o}}$ is $\underline{\mathrm{F}}$. In illusory cases, $\underline{\mathrm{o}}$ is presented, and, although not actually $\underline{\mathrm{F}} \underline{\underline{\mathrm{o}}}$ is visually relevantly similar to paradigm $\underline{F}$ 's in ways which may come to be appreciated and understood by the subject. Either way, the nature of o provides a fully perspicuous explanation of the subjective nature of the experience of it, given the point of view and other circumstances involved. $\underline{\mathrm{O}}$ is the object which explains, in a way which is accessible to the subject, how things look. In this sense, it constitutes the core subjective character of his experience. Of course, like 'intelligibility' above, and indeed relatedly, 'perspicuity' here is in need of serious explication. The kind of explanation I have in mind as perspicuous has its paradigm in Locke's (1975) mechanistic talk of cogs turning in a clock or keys in a lock, in contrast with the non-perspicuous explanation involved in modern fundamental physical appeals to brute correlations amongst unobservables. The fact that a circular glass top looks elliptical from a certain angle, say, is akin to the former and quite unlike the latter, although I acknowledge that this is well short of any proper characterization of the relatively a priori status of perspicuous explanation.

Second, my own characterization of illusions involves categorization: they are experiences in which $\underline{\underline{o}}$ looks $\underline{\mathrm{F}}$ although $\underline{\underline{o}}$ is not $\underline{\mathrm{F}}$. Yet this surely entails an assimilation of (OV) to (CV). Perhaps; but it does not collapse (OV) into a version of (CV). For (CV) attempts to capture the most basic subjective character of perceptual experience in wholly contentful terms, whereas (OV) explains the truth of looks claims, involving the categorization which they clearly do, as the product of a more basic subjective 
presentation of a particular object, along with its salient visually relevant similarities with various paradigms in the circumstances.

Consider analogously Grice on conversational implicature (1989a, 1989b). It is a datum that we communicate a highly complex message in speaking a language which our audience understand. Grice's opponents regard every aspect of this as part of an undifferentiated notion of meaning. Grice insists, on the contrary, upon a partition into core semantic meaning and any pragmatic implicature which may be conveyed by choosing to say something with just those truth-conditions in the circumstances, given the conventions governing good communication. Similarly, I claim that, although 'unequal in length', for example, really is part of how the (ML) lines look, it is right to regard this as the product of a more basic subjective presentation of those very lines themselves, along with an account of how they may intelligibly strike us, from that viewpoint, in those conditions, given our training, conceptual endowment, attention and interests at the time. Looks in general flow from the core early modern empiricist insight at the heart of (OV), given independently motivated additional theoretical materials. They are not to be accommodated by any direct and undifferentiated appeal to a barrage of perceptual contents which are simply served up to us in experience. Thus, I claim that the $(\mathrm{OV}) /(\mathrm{CV})$ contrast remains robust.

I conclude that (3) is to be rejected. We need not, nor is it in the end defensible to, reject (3) by resorting to today's (CV) orthodoxy, though. (1) and (2) are true absolutely as they are. The phenomena of illusion, and indeed hallucination, are perfectly compatible with 
the idea that mind-independent physical objects are the direct objects of perception, in my sense of themselves constituting the core subjective character of perceptual experience. Content only enters the characterization of perception as a result of an intellectual abstraction or generalization from the basic nature of such experience. In this way, I claim, empirical realism is fully vindicated. ${ }^{14}$

\section{References}

Berkeley, G. 1975a. Three Dialogues Between Hylas and Philonous. In M. Ayers (ed.), George Berkeley: Philosophical Works. London: Everyman.

- $\quad$ 1975b. A Treatise Concerning the Principles of Human Knowledge. In M. Ayers (ed.), George Berkeley: Philosophical Works. London: Everyman.

Brewer, B. 1999. Perception and Reason. Oxford: Oxford University Press.

- $\quad$ Forthcoming. 'Berkeley and Modern Metaphysics'.

- $\quad$ Forthcoming. 'How to Account for Illusion'. In A. Haddock and F. Macpherson (eds.), Disjunctivism. Oxford: Oxford University Press.

- $\quad$ Forthcoming. 'Perception and Content'. European Journal of Philosophy.

- Forthcoming. Perception and its Objects. Oxford: Oxford University Press.

Campbell, J. 2002. Reference and Consciousness. Oxford: Oxford University Press.

\footnotetext{
${ }^{14}$ Many thanks to Justin Broackes, Nicolas Bullot, Steve Butterfill, John Campbell, David Charles, Bill Child, Tim Crane, Imogen Dickie, Naomi Eilan, Anil Gupta, John Hawthorne, Christoph Hoerl, Hemdat Lerman, John McDowell, Jennifer Nagel, Johannes Roessler, Nick Shea, Alison Simmons, Paul Snowdon, Matt Soteriou, Helen Steward, Charles Travis, Ralph Wedgwood, Michael Williams, and Tim Williamson, for helpful comments on previous versions of this material.
} 
Evans, G. 1982. The Varieties of Reference. Oxford: Oxford University Press.

Fodor, J. 1998. Concepts: Where Cognitive Science Went Wrong. Oxford: Oxford University Press.

Grice, H. P. 1989a. 'Logic and Conversation'. In his Studies in the Way of Words. Cambridge, Mass: Harvard University Press.

- $\quad$ 1989b. 'Further Notes on Logic and Conversation'. In his Studies in the Way of Words. Cambridge, Mass: Harvard University Press.

Jastrow, J. 1900. Fact and Fable in Psychology. New York: Houghton Mifflin.

Lewis, D. 1998. 'The Problem of Temporary Intrinsics: an Excerpt from On the Plurality of Worlds'. In P. Van Inwagen and D. W. Zimmerman (eds.), Metaphysics: The Big Questions. Oxford: Blackwell.

- 2002. 'Ramseyan Humility'. Gareth Evans Memorial Lecture to Oxford University, delivered posthumously by Stephanie Lewis, 2.iii.02.

Locke, J. 1975. An Essay Concerning Human Understanding, ed. P. H. Nidditch. Oxford: Oxford University Press.

McDowell, J. 1994. Mind and World. Cambridge, Mass: Harvard University Press.

Martin, M. 2004. 'The Limits of Self-Awareness'. Philosophical Studies, 120, 37-89.

Peacocke, C. 1992. 'Scenarios, Concepts and Perception'. In T. Crane (ed.), The Contents of Experience. Cambridge: Cambridge University Press.

Phillips, I. Draft. 'Illusion and Content'. Paper presented at the 2005 Warwick University Mindgrad Conference.

Snowdon, P. 1992. How to Interpret “Direct Perception”". In T. Crane (ed.), The Contents of Perception. Cambridge: Cambridge University Press. 
Stoneham, T. 2002. Berkeley's World. Oxford University Press.

Wittgenstein, L. 1958. Philosophical Investigations. Oxford: Blackwell. 